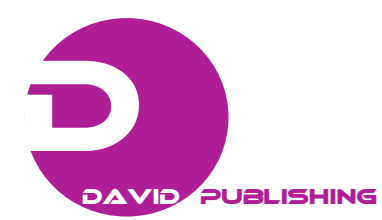

\title{
The Practice Case of Food Hygiene 7S Action in Akafuku Corporation
}

\author{
Motoki Yamaguchi* and Tatsuo Tanaka \\ 2015 Asama-cho, Ise City, Mie Pref, Japan \\ *Corresponding author's e-mail: yamaguchi@akafuku.co.jp
}

\begin{abstract}
Akafuku was established about 300 years ago in 1707 as a tea house in Ise to welcome those visiting the Ise Grand Shrine, and has achieved great results in systematical management of hygiene aiming for company-wide constitutional improvement in the wake of restarting operation in 2008; the efforts are based on 7S action for food hygiene. The food hygiene 7S action comprises seven Japanese phrases regarding food hygiene, that is, Seiri, Seiton, Seisou, Senjou, Sakkin, Shitsuke and Seiketu, and each means disposition, arrangement, sweeping, laundering, sterilization, training and cleaning, which are implemented so as to eliminate even microbe. The hygiene management is promoted by preventing microbe's growth, decreasing and killing them. In Akafuku, 7S committee is set up as a promotion organization, whose members are company president as a chairman, representatives of each department and external specialists; it proceeds according to annual plan. The concrete examples of 7S action are as follow, i) reporting the current state of company-wide hygiene management, ii) informing the main improvements related to HACCP or PRP, iii) improving through indication at 7S patrol or on voluntary basis in each department, the number of improvements is as much as 400 cases per year. Moreover, food hygiene 7S action also works for implementing HACCP system and prerequisite program (PRP) on ISO22000 certainly and effectively. In fact, Akafuku gained approval by Mie Prefecture HACCP method introducing institution in 2010, and furthermore certification of ISO22000 in 2011.
\end{abstract}

Key words: Hygiene practice, food hygiene 7S, HACCP, ISO22000, Akafuku corporation. 